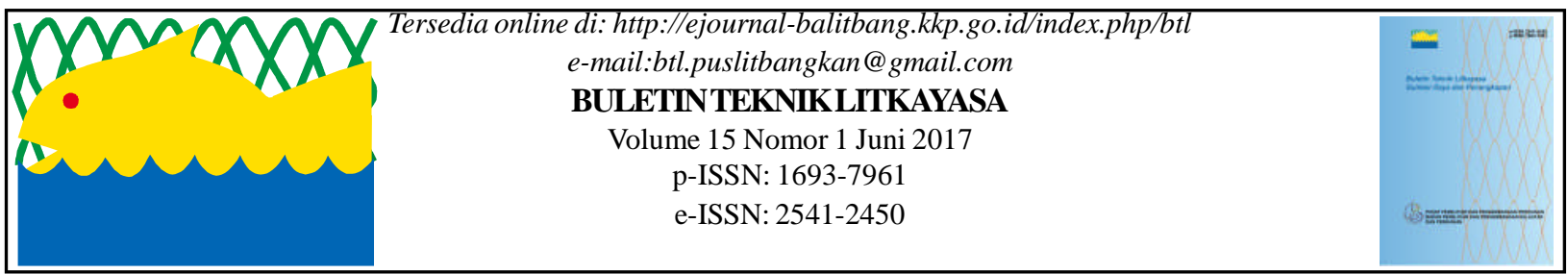

\title{
UJI COBA FILTER KOMPRESOR ANGIN DALAM PENANGKAPAN IKAN YANG RAMAH LINGKUNGAN
}

\author{
Syamsul Arifin', Nugroho dan Agus Sudarto \\ ${ }^{1} T e k n i s i$ Litkayasa pada Balai Besar Penangkapan Ikan Semarang \\ Teregistrasi I tanggal: 06 Maret 2017; Diterima setelah perbaikan tanggal: 08 Juni 2017; \\ Disetujui terbit tanggal: 13 Juni 2017
}

\section{PENDAHULUAN}

Penggunaan kompresor tradisional / tambal ban sangat berbahaya untuk pekerjaan bawah air, karena tidak terdapat filter penyaringan udara serta penggunaan oli sintetis yang berasal dari minyak bumi sebagai pelumas. Kasus yang terjadi pada penyelam kompresor tradisional adalah udara yang masuk ketabung tekanan tinggi tidak terfilter dengan baik dan asap dari mesin penggerak kompresor masuk bercampur kedalam tabung yang akan dihirup oleh penyelam. Udara permukaan terkontaminasi $\mathrm{CO} 2$ dengan konsentrasi 5-6\% maka dapat mengakibatkan sesak napas, napas cepat, dan pusing. Pada kadar $10 \%$, tekanan darah akan turun dan menyebabkan kehilangan kesadaran. Pada kadar $\mathrm{CO} 2$ yang lebih tinggi yaitu $12-14 \%$ penyelam akan mengalami depresi pernapasan dan saraf pusat yang mengakibatkan kematian (Bailey et al., 2005).

Menurut Luthfi \& Muzaky (2015) peralatan yang aman digunakan oleh penyelam adalah Scuba (selfcontained underwater breathing apparatus). Peralatan Scuba relative lebih mahal menyebabkan nelayan memilih menggunakan kompresor tambal ban disamping minimnya pengetahuan tentang standar keamanan dan kesehatan serta teknik penyelaman yang aman. Kegiatan uji coba filter kompresor angin ini diharapkan bisa menjadi salah satu solusi untuk mengatasi permasalahan yang ada dilapangan.

Tujuan dari kegiatan uji coba filter kompresor adalah merekayasa filter yang dipasang pada kompresor agar aman bagi penyelam dalam penangkapan ikan yang ramah lingkungan.

\section{POKOK BAHASAN \\ Waktu dan Lokasi}

Kegiatan uji coba filter kompresor dilaksanakan di Balai Besar Penangkapan lkan dengan 3 tahapan yang meliputi:
1. Persiapan, dilaksanakan pada bulan Februari Maret 2016 di Kabupaten Jepara Jawa Tengah.

2. Desain dan pembuatan filter kompresor, dilaksanakan pada bulan april - mei 2016, di Balai Besar Penangkapan Ikan Semarang.

3. Pengujian filter kompresor dilaksanakan pada bulan oktober - nopember 2016 di Balai Besar Teknologi Pencegaahan Pencemaran Industri Kota Semarang.

\section{Bahan dan Metode \\ Bahan}

Bahan yang digunakan adalah kompresor tekanan rendah, kompresor tekanan tinggi dan filter kompresor.

\section{Peralatan} printer:

Peralatan yang digunakan adalah gas analyzer dan

1. Gas analyzer: Suatu peralatan instrumentasi yang digunakan untuk mengukur komposisi dan proporsi dari suatu campuran gas. Gas analyzer yang digunakan pada kegiatan uji coba ini adalah:
- Bacharach Portable Combustion
Analyzer(PCA3) dan Technotest 488 gas analyzer

2. Portable Wireless Infrared Printer (w/disposable batteries) Part No.24-1400.

\section{Metode}

Metode yang digunakan dalam uji coba filter kompresor angin dilakukan pengukuran langsung kualitas udara dengan parameter sebagai berikut:

1. Kualitas udara normal

2. Kualitas udara yang dihasilkan kompresor tekanan tinggi (kompresor untuk mengisi tabung scuba)

3. Kualitas udara yang dihasilkan oleh kompresor tekanan rendah 
4. Kualitas udara yang dihasilkan oleh kompresor tekanan rendah yang telah dilengkapi filter hasil rekayasa.

Dalam kegiatan uji coba filter kompresor data yang digunakan meliputi data primer dan sekunder. Data primer diperoleh dari pengujian langsung filter kompresor dan wawancara dengan nelayan maupun dinas terkait penyelaman kompresor. Sedangkan data sekunder meliputi studi literatur mengenai kompresor selam dan penyelaman kompresor untuk penangkapan ikan. Adapun tahapan dalam pengumpulan data dalam kegiatan ini untuk mendapatkan desain rinci filter kompresor yang akan dioperasiakan:

1. Melakukan pendataan jenis-jenis penangkapan ikan dengan menggunakan kompresor

2. Penjajagan untuk mendapatkan informasi awal mengenai aspek teknis dan administratif di Kabupaten Jepara.

3. Pengkajian untuk merancang filter kompresor

4. Pembuatan desain dan benda uji filter kompresor

5. Uji darat kualitas udara yang dihasilkan (skala Lab) filter kompresor.

\section{Hasil}

Dari hasil kegiatan penjajagan uji coba filter kompresor yang dilaksanakan di Karimunjawa (Kabupaten Jepara) melalui pengamatan secara langsung dan wawancara dengan beberapa nelayan diperoleh hasil sebagai berikut:

1. Sebagian besar nelayan Karimunjawa sudah tidak menggunakan kompresor angin dalam operasi penangkapan ikan

2. Kesadaran para nelayan akan bahaya yang ditumbulkan akibat penggunaan kompresor yang telah terjadi seperti gangguan pendengaran, saraf, kelumpuhan sampai kematian

3. Para nelayan sudah beralih kepada alat tangkap kategori ramah lingkungan

Berdasarkan hal tersebut, maka sebagian besar nelayan merasa keberatan bila kegiatan uji coba filter kompresor dilakukan di Karimunjawa, mengingat sebagian besar sudah meninggalkan kompresor dalam penagkapan ikan.

\section{Desain Filter kompresor}

Filter kompresor yang digunakan pada uji coba ini mempunyai beberapa parameter yang harus dipenuhi yaitu: Didesain mudah dipindahkan dan tidak terangkai menyatu dengan kompresor (portable), dapat memisahkan air dari udara dan mampu mereduksi gas karbon, menghasilkan udara bertekanan rendah yang siap digunakan / konsumsi penyelam secara langsung, panjang selang udara yang digunakan tidak lebih dari 15 meter (untuk keamanan). Dari parameter tersebut, maka desain filter terbagi dalam beberapa bagian (Gambar 1).
1. Kerangka
Untuk menyangga atau menyatukan komponen-komponen filter.
2. Input Mendistribusikan udara yang dihasilkan kompresor ke separator
3. Separator Memisahkan kandungan air yang berada pada udara yg berasal dari kompresor
4. Filter Mereduksi gas-gas beracun pada udara yang dihasilkan oleh kompresor, terutama gas karbon monoksida(CO)
5. Output Membagi udara yang keluar setelah melalui filter kedalam beberapa keluaran
6. Konector yang terhubung dengan selang dan mouthfish. Penghubung komponen separator dan filter.

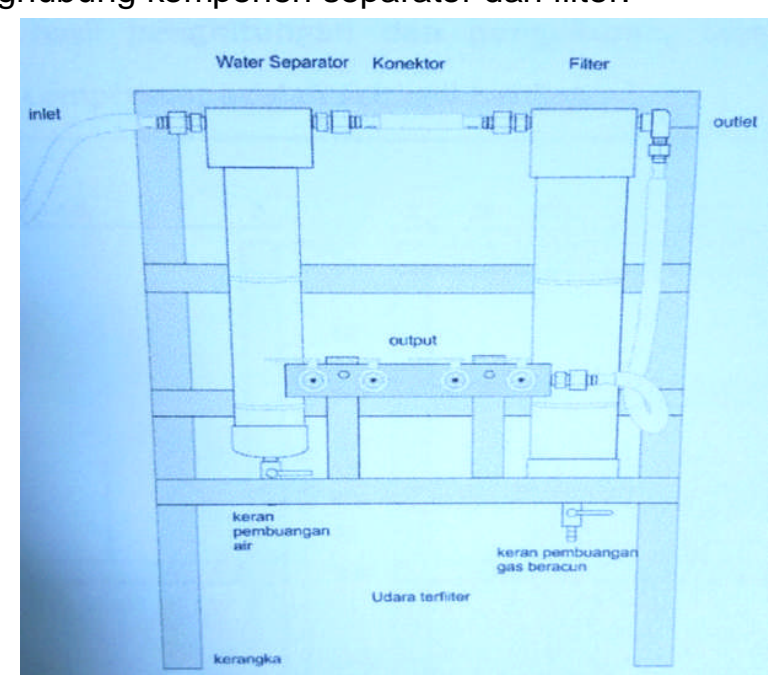

Gambar 1. desain filter kompresor. 
Sistem kerja filter kompresor merupakan alur aliran udara yang dihasilkan kompresor hingga mencapai out put yang siap dikonsumsi oleh penyelam, adapun alur udaranya sebagiberikut (Gambar 2):

- Udara yang dihasilkan kompresor disalurkan melalui selang input menuju water separator

- Pada separator udara yang masih mengandung air akan dipisahkan selanjutnya air akan dikeluarkan melalui keran pembuangan, sedangkan udara akan

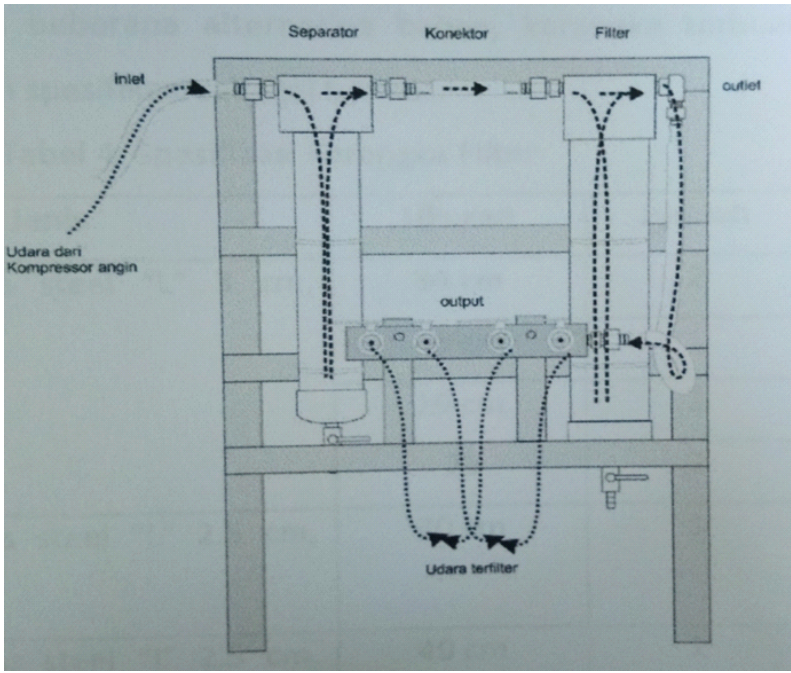

Gambar 2: Alur sirkulasi udara pada filter kompresor.

Filter udara yang berfungsi untuk mereduksi gasgas beracun pada udara yang dihasilkan kompresor, beberapa bahan yang digunakan pada desain filter ini meliputi katride yang terdiri dari silica besar (diameter $4 \mathrm{~mm}$ ), silica kecil (diameter $2 \mathrm{~mm}$ ) dan spon.

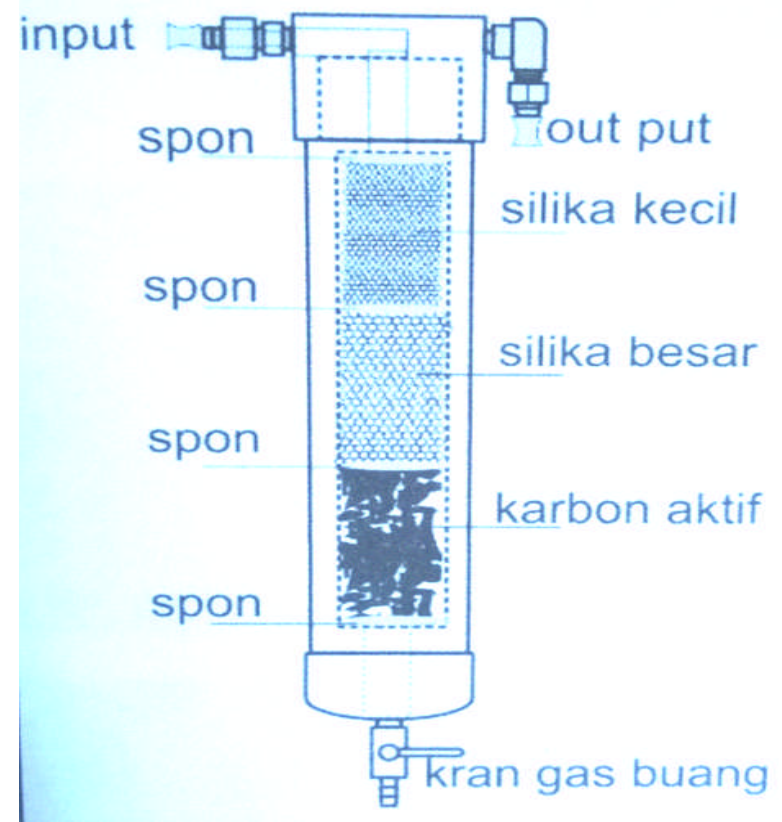

Gambar 4: Komponen filter kompresor. disalurkan ke filter melalui konektor (Gambar 3).

- Didalam filter kompresor udara akan mengalami penyaringan terhadap gas-gas beracun seperti karbon monoksida sebelum dikeluarkan melalui outlet menuju komponen output.

- Pada komponen output, udara didistribusikan melalui beberapa keran yang terhubung keselang mouthfish.

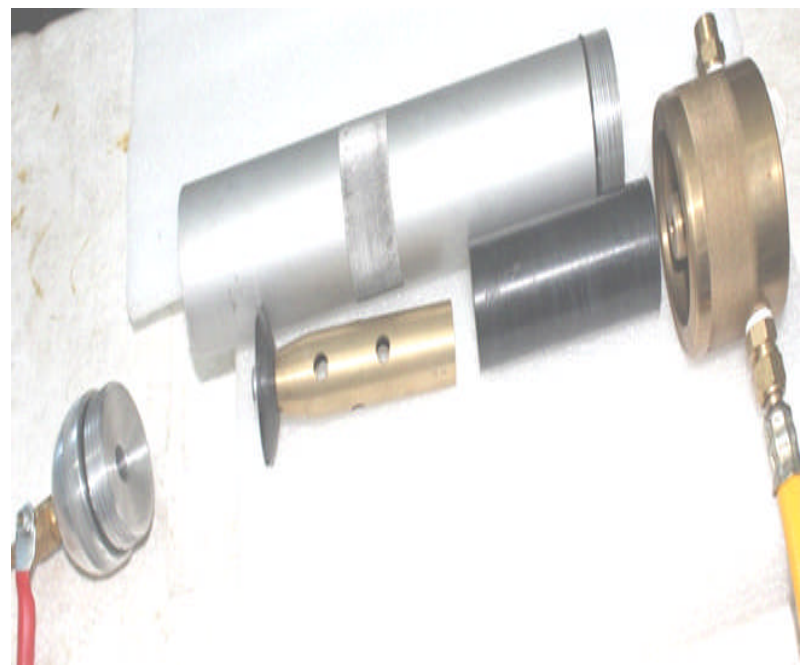

Gambar 3: Foto separator.

Sedangkan bahan pelindung (tabung) terbuat dari aluminium yang tahan tekanan tinggi. Sedangkan untuk bahan utamanya menggunakan karbon aktif, yang berfungsi untuk menyerap gas-gas beracun. Komponen filter kompresor disajikan pada Gambar 4 - 7.

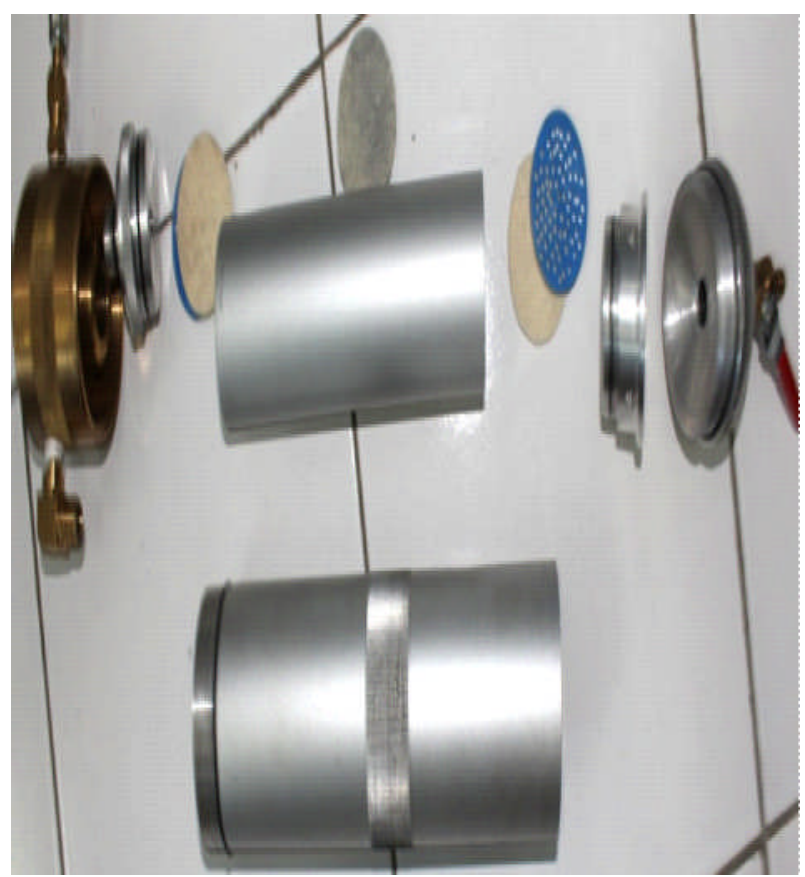

Gambar 5. Foto komponen filter kompresor. 


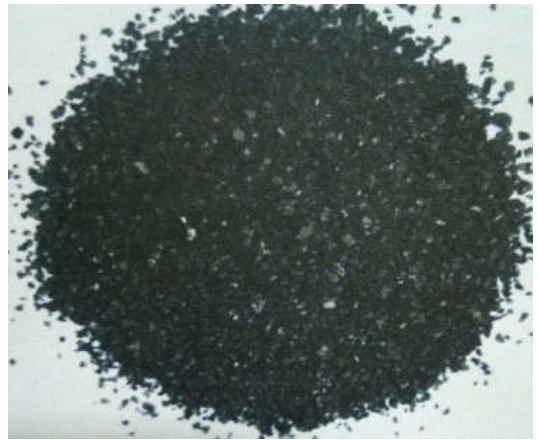

Gambar 6. Karbon aktif

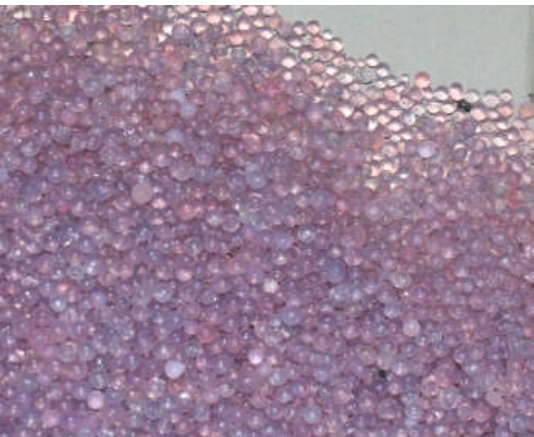

Gambar 7. Silica besar dan kecil

Hasil pengujian kualitas udara yang berasal dari kompresor shark 12 liter disajikan pada Tabel 1 - 4 .

Tabel 1. Hasil pengujian menggunakan Bacharach Portable Combustion Analyzer (PCA3)tanpa filter kompresor

\begin{tabular}{lllll}
\hline No & Parameter & Satuan & Hasil Terukur & Metode Uji \\
\hline 1 & Karbon Monoksida (CO) & $\mathrm{mg} / \mathrm{m}^{3}$ & 34.0 & SNI 19-7117.10-2005 \\
2 & Oksigen (O2) & $\%$ & 20.8 & SNI 19-7117.10-2005 \\
\hline
\end{tabular}

Tabel 2. Hasil pengujian menggunakan TECHNOTEST 488 Gas Analyzer tanpa filter kompresor

\begin{tabular}{lllll}
\hline No & Parameter & Satuan & Hasil Terukur & Metode Uji \\
\hline 1 & Karbon Monoksida (CO) & $\%$ & 19.9 & - \\
2 & Oksigen (O2) & $\%$ & 20.8 & - \\
\hline
\end{tabular}

Tabel 3. Hasil pengujian menggunakan Bacharach Portable Combustion Analyzer (PCA3) menggunakan filter kompresor

\begin{tabular}{lllll}
\hline No & Parameter & Satuan & Hasil Terukur & Metode Uji \\
\hline 1 & Karbon Monoksida (CO) & $\mathrm{mg} / \mathrm{m}^{3}$ & 16 & SNI 19-7117.10-2005 \\
2 & Oksigen (O2) & $\%$ & 20.9 & SNI 19-7117.10-2005 \\
\hline
\end{tabular}

Tabel 4. Hasil pengujian menggunakan TECHNOTEST 488 Gas Analyzer dilengkapi dengan filter kompresor

\begin{tabular}{lllll}
\hline No & Parameter & Satuan & Hasil Terukur & Metode Uji \\
\hline 1 & Karbon Monoksida (CO) & $\%$ & 0 & - \\
2 & Oksigen (O2) & $\%$ & 20.8 & - \\
\hline
\end{tabular}

\section{KESIMPULAN}

1. Filter kompresor yang didesain terdiri dari water separator (untuk memisahkan air dan fluida lainya dari udara), filter untuk mereduksi gas-gas beracun yang terkandung dalam udara

2. Parameter pengujian filter kompresor adalah oksigen (O2) dan karbon monoksida (CO)

3. Dari hasil pengujian dapat diketahui bahwa filter kompresor angin mampu mereduksi kandungan air dan fluida lainya serta karbon monoksida (CO) hingga $50 \%$.

\section{Saran}

1. Penggunaan tabung filter kompresor sebaiknya menggunakan bahan stainlesstil.

2. Penambahan parameter uji yang meliputi gas-gas lainya
3. Penggunaan oli pada kompresor harus menggunakan oli nabati.

4. Perlunya sosialisasi prosedur penyelaman yang aman terhadap para nelayan yang menggunakan kompresor.

\section{DAFTAR PUSTAKA}

Luthfi \& Muzaky. 2015. Perbaikan standar keamanan penyelaman nelayan kompresor

Bailey,J.E., Argyropoulus, S.V., Kendrick, A. H., and Nutt, D.J. 2005. Behavioral and cardiovascular effects of $7.5 \% \mathrm{CO} 2$ in human volunteers. Depression and anxiety, 21(1), 18-25. 